\title{
Is land cover an important asset for addressing the subjective landscape dimensions?
}

\author{
Sónia Carvalho-Ribeiro ${ }^{\mathrm{a}, *}$, Isabel Loupa Ramos ${ }^{\mathrm{b}, 1}$, Luís Madeira ${ }^{\mathrm{a}, 2}$, Filipe Barroso $^{\mathrm{a}, 2}$, \\ Helena Menezes ${ }^{\mathrm{a}, 2}$, Teresa Pinto Correia ${ }^{\mathrm{a}, \mathrm{c}, 2}$ \\ a ICAAM-Instituto de Ciências Agrárias e Ambientais Mediterrânicas, University of Évora (UE), Núcleo da Mitra, Edificio Principal, Gab 202, Apartado 94, \\ 7002-554 Évora, Portugal \\ b CESUR, Technical University of Lisbon, Av. Rovisco Pais, 1049-001 Lisbon, Portugal \\ ${ }^{c}$ DPAO, Department Landscape Environment and Planning, University of Évora (UE), Portugal
}

\section{A R T I C L E I N F O}

\section{Article history:}

Received 20 June 2012

Received in revised form 9 April 2013

Accepted 27 April 2013

\section{Keywords:}

Cultural landscapes

Indicators

Landscape identity

Social representations

Alentejo

Portugal

\begin{abstract}
A B S T R A C T
This paper explores which physical landscape components relate to subjective landscape dimensions. The ways in which people describe their surrounding cultural landscape was analyzed through an assessment of their representations of it. A special focus was placed on assessing the role of land cover as a means to communicate landscape meanings regarding a specific geographical region. The methodological framework was built on the basis of a questionnaire survey, multivariate statistical analysis and mapping approaches. This research shows that there is a set of physical landscape components that relate to subjective landscape dimensions which can be disclosed through the assessment of social representations. Enhancing and safeguarding those physical landscape components associated with the subjective landscape dimensions are important aspects in both framing and targeting land cover/use policies and decision making. Results also suggest that land cover can be understood as an important asset for describing landscapes as more than $30 \%$ of respondents referred to it when asked to represent the case study region of Alentejo in southern Portugal. This might mean that in addition to objective ecological and biological functions, land cover is also an important asset for evaluating subjective landscape dimensions in line with place attachment and landscape identity. Finally, the ways in which the empirical material gathered here can be used to inform policy and planning are explored.
\end{abstract}

(c) 2013 Elsevier Ltd. All rights reserved.

\section{Introduction}

Landscape has been widely recognized as a multilayered concept embedding both objective and subjective dimensions (Antrop, 2000; Naveh, 2000, 2007; Tveit et al., 2006; Hunziker et al., 2007; Nassauer, 2011). A robust set of studies addresses objective landscape dimensions (e.g. characterizing landscape in terms of land cover patterns, species richness and ecological zones) (Daily and Matson, 2008; Turner and Daily, 2008; Chapin et al., 2010). There is also a considerable body of knowledge on the subjective dimensions (e.g. aesthetic satisfaction derived from a landscape) (Palang and Fry, 2003; Stephenson, 2007; Nijnik et al., 2009; Swanwick, 2009; Ode et al., 2010). But the ways in which these two bodies

\footnotetext{
* Corresponding author. Tel.: +351 266 740800x4445.

E-mail addresses: sribeiro@uevora.pt, sonia.carvalhoribeiro@googlemail.com (S. Carvalho-Ribeiro), isabel.ramos@ist.utl.pt (I.L. Ramos), lmadeira@uevora.pt (L. Madeira), flb@uevora.pt (F. Barroso), hgm@uevora.pt (H. Menezes), mtpc@uvora.pt (T. Pinto Correia).

1 Tel.: +351218417000

2 Tel.: +351 $266740800 \times 4445$.
}

of research can be bridged in order to inform policy making has been hampered by focused disciplinary approaches (Bishop and Phillips, 2004; Antonson, 2009; Beunen and Opdam, 2011). Should this handicap be overcome, it is likely that the multiple relationships between people and their surrounding physical and objective landscape settings, as well as the subjective meanings associated with them, might offer valuable knowledge for enhanced planning and management for future landscapes (Opdam et al., 2001; Antrop, 2005; von Haaren and Ott, 2008).

With an overall aim of bridging objective and subjective landscape dimensions in order to inform landscape policy and planning, this paper specifically assesses how a physical landscape component such as land cover can be deployed for addressing subjective landscape dimensions in the cultural landscapes of Europe. This knowledge should prove to be of value for better targeting land cover/use policy-making at multiple levels of governance (Faludi, 2009). In the rural landscapes of Europe the Common Agricultural Policy (CAP) is often pointed out as one of the most important drivers of landscape change (EP, 2011). But the impact of spatial planning in Member States, even though primarily dealing with urban growth, transportation and other infrastructures, should also 
not be ignored as an important influence over land cover change. Hence, the focus heretofore has been placed on land cover because, while there are other physical landscape features such as castles or rivers that might be associated with subjective and imaginary landscape dimensions, those cannot readily be linked to land cover/use policy options in a straightforward manner, whereas links with land cover can be established. In order to address this issue, this paper specifically aims at assessing how land cover may contribute to bridge objective and subjective dimensions in cultural landscapes of Europe in such ways which can be made relevant for policy and planning.

Furthermore, while some of the relationships between land cover and a set of ecological and biological processes have been widely addressed in the literature, we argue that the role of land cover as surrogate for the subjective landscape dimensions still needs to be explored. Although land cover data has also been used on social science surveys namely on landscape preferences studies, most of the work developed on landscape preferences have focussed on user based preferences for different land covers in order to assess the ways in which a certain user "likes" one land cover better than another for a specific amenity activity (Dramstad et al., 2006; Tveit et al., 2006; Sayadi et al., 2009; Swanwick, 2009; Carvalho-Ribeiro and Lovett, 2011). But whether or not land cover is also an important asset for addressing other subjective landscape dimensions has yet to be fully explored.

Therefore, one of the contributions of this study is comprehensively to tackle the social dimensions of landscapes. As pointed out by Lorzing (2001) there are at least four layers associating humans and landscape: (i) intervention - the landscape is what we make, (ii) knowledge - landscape as associated with facts we know, (iii) perception - the landscape is what we see (visual landscape), and (iv) interpretation - the landscape which we believe. Throughout this paper the associations between the layer of intervention, which deals primarily with the relationship of peoples' influence on landscape, by for example changing land cover as a consequence of policy options, and the layers of knowledge, interpretation and perception, associated with landscape's influence on people, can be comprehensively explored.

Our primary goal is to assess the extent to which people refer to land cover when asked to represent a certain landscape. But a broader and more general aim is to explore the physical landscape components or settings which people are willing to appreciate regarding a specific cultural landscape of Europe. By landscape components and settings we mean aspects such as: specific places (a specific geographical location), landscape features and elements (either natural or manmade such as castles, churches, rivers) as well as land cover types (either single - e.g. broadleaf forest) or its patterns (compositions of land covers - e.g. mosaic of pine, cereal and oak trees). The work was developed by: (1) surveying the ways in which people communicate about their surrounding landscape to others, through an assessment of their representations and (2) exploring the ways in which people's representations can be mapped and ultimately integrated into policy and decision making.

It follows from the above that a central concept developed here is that of social representation. This is understood as the elaboration of a social object by either the individual or its community for the purpose of behaving and communicating (Moscovici, 1963; Quétier et al., 2010). The concept of representation has been developed within psychology to help explain the many ways humans create and relate to their social worlds. Representations are used to communicate a discursive image (language or code) with a goal to legitimate a discourse (Vepsäläinen and Pitkänen, 2010). Therefore, a representation expresses different ways in which people communicate their interpretations and self-creations. It is thus likely that when people are asked to communicate about a known landscape they will draw on features that best convey their relations to that specific landscape. So, this study builds upon other studies which relate to the manner in which landscape meaning has drawn on the concept of social representation in order to gain insights into the meanings that specific landscape features have for people by analyzing their descriptions of it (della Dora, 2009; Quétier et al., 2010; Vepsäläinen and Pitkänen, 2010; Buijs et al., 2011). In this context, a set of crucial questions still need to be raised: what are the physical aspects of landscapes which people cherish and ultimately want to communicate about when addressing their surroundings through their everyday lives? What are the landscape components which nowadays are still able to convey coherence and identity for a multitude of new landscape users in the cultural landscapes of Europe?

Throughout this work it was hypothesized that if land cover is a good surrogate for communicating about a specific landscape, then people would refer explicitly to this when asked to represent a certain landscape. Taking this perspective on board, for the initial hypothesis to be confirmed, land cover would have to be relevant enough to set the basis for the construction of people's representations.

Nevertheless, to explore subjective landscape dimensions through the concept of representation, although holding considerable exploratory potential, introduces a complex and intricate conceptual framework that deserves special methodological attention. It is out of the purpose of this work, to focus on those deep-grounded sociological and psychological concepts underlying the reasons for the representations themselves. Instead, we aim at exploring the more tangible forms of the concept by focusing on the landscape and the way people use landscape physical features, e.g. the land cover, to communicate about a specific geographic region.

Thus it is important to set out the theoretical framework concerning the ways in which people represent the landscape of their surroundings. A huge body of literature points out the importance of identity associated with landscape (Tilley, 2006; Olwig, 2007; Pedroli et al., 2007). Landscape is described in the UNESCO's World Heritage designation of Cultural Landscapes "as part of peoples' collective identity", and in the European Landscape Convention (ELC) as the "foundation of their identity" (Article 5a).

To our knowledge, there is only a small amount of literature that systematically explores the essential aspects/features of the landscape that enforce collective or individual identity. Nor does there seem to be much research as to what thresholds of landscape change are deemed acceptable until such changes "disconnect" from people. Selman (2012, p. 5) puts this rupture as follows: there will be "erosion of bonds between people and place". This paucity of literature may be due to the concept of identity as being primarily theorized in the disciplinary domain of social sciences which has been shy on emphasizing space as creator of identity (Proshansky et al., 1983). Although the concept of "spatial identity" was introduced in 1946 by Erickson it has only relatively recently been developed by Proshansky et al. (1983) as the concept of "place identity". Furthermore, some ambiguity has been created in landscape literature when using the concept of "landscape identity". Who is the subject of identity? Is it the "landscape" or the "people"? What is the scale at which landscape can foster the formation of identity; local, regional or even European? Sassatelli (2010).

These approaches draw on Social Identity Theory (Tajfel, 1981; Ashforth and Mael, 1989), where in a simplistic way, two types of identity might be distinguished. One lies within a group (ingroup), stressing what links the members of this specific group make definable and recognizable, and that which extends towards another group (out-group), emphasizing what is different (Tajfel, 1981). Applying this to the landscape scale, what connects the ingroup evaluations might be features of the landscape that have a common meaning to (for those that live or use that landscape), 
based for instance, on their past or present experience in their specific landscape, or rituals linked to agricultural practices. According to Bernardo and Palma-Oliveira (2012), these features of which respondents are likely to communicate about might be positive or negative, as long as they are relevant enough to activate the sense of belonging to that landscape.

On the other hand, when communicating with an out-group, to someone from another landscape, features or attributes of the respondent's own landscape might be evoked that not only convey the difference, but also what they know is valued by the others, as they aim to communicate the best possible image about themselves. Therefore, in this process of choice of the landscape features to be evoked to an out-group, people from a specific landscape might consider a combination of what they value themselves and what they think the others (considered by them as a representative out group) would value (Nigbur and Cinnirella, 2007; Bernardo and Palma-Oliveira, 2012).

As previously mentioned, another issue this paper explores is the importance of land cover as a way to bridge subjective and subjective landscape dimensions. To further develop this argument, it is important first to disentangle the differences between land cover and land use, namely by considering land cover as vegetation structures (grass, pine tree, etc.) while land use considers the use humans make of a piece of land (residential, agriculture) (Verburg et al., 2009). Although it is not straightforward to derive land use data based on land cover, there are widespread arguments supporting land cover as a useful landscape indicator. Those arguments arise mainly from five standpoints: (1) land cover is one the most dynamic factors across the earth surface and also is one of the most visible and responsive landscape' layers (Claessens et al., 2009; Verburg et al., 2011); (2) a robust body of research on both environmental and biological sciences has been able to establish straight relationships between land cover related indicators and innumerous biological/ecological processes (e.g. percentage of forest cover with bird species distribution); (3) using land cover as data driven support has obvious advantages, since there are available land cover maps at different spatial scales (e.g. CORINE at the European scale) which are regularly updated through remote sensing; (4) as previously stated land cover can be addressed at the policy level, being possible to establish relationships between land cover and policy driven measures; and finally (5) the mix of individual land covers (land cover patterns) can be linked to a set of land uses (Carvalho Ribeiro et al., 2013; Pinto Correia and Carvalho Ribeiro, 2012), and this might offer valuable knowledge for more sustainable planning and management for future landscapes (Opdam et al., 2001; Antrop, 2005; von Haaren and Ott, 2008).

It follows from the above that all these matters concerning land cover are of outmost importance in the planning and environmental policy context which either constrain or promote land cover change for accommodating, for example, urban uses or transportation infrastructures. Also CAP reforms since the nineties have been exploring ways to shift the focus from food production support to new functions of agriculture taking advantage of new societal demands for rural landscapes in Europe. These new demands have to be clearly identified in order to be accommodated in both agricultural and environmental policies as well as being properly embedded in spatial planning documents at the regional and local scales. Hence, this research is based on the acknowledgement that there is a growing policy interest on attempting to enhance and safeguard the "cultural landscapes of Europe" namely by looking for ways for acknowledging landscapes to which people become attached.

To explore this conceptual ground our analysis is based on a specific study in the Alentejo region in southern Portugal. The specific questions this paper addresses are summarized as follows:
1. Which are the landscape components (i) places (e.g. specific geographical locations), (ii) landscape features/elements (e.g. topography/castle) and/or (iii) land covers (e.g. single or land cover patterns) used by people to represent the cultural landscape of the Alentejo region?

2. How far is land cover as an important asset for communicating about the Alentejo landscape?

3. Is it possible to map those sets of land covers "representing" the Alentejo landscape?

4. How useful is this knowledge for better targeting policy and planning?

\section{Study area and methods}

\section{Study area}

Alentejo is located in southern Portugal, its administrative organization comprising a set of 47 municipalities covering an area of $31,551 \mathrm{~km}^{2}$ representing a third of the area of the country (Fig. 1). Although there are differences across the area, Alentejo is well known in Portugal for its characteristic rolling plains and flat land landscapes as well as by its dry Mediterranean climate. In addition Alentejo is also appreciated for its historical and cultural heritage concentrated in small to medium urban areas surrounded by a countryside landscape. Alentejo's major city - Évora - has been classified in 1986 by UNESCO as World Heritage town. Also in rural areas it is common that each small village or town centre holds ancient castles, churches or yet other heritage buildings. A prominent land cover class is the montado agro-forestry system.

\section{Methods}

In order to answer to the research questions raised above three methodological steps were undertaken:

(i) Data collection: A questionnaire survey was prepared and conducted in the Alentejo region of Portugal;

(ii) Data categorization and analysis: Content and statistical analysis were used to summarize and describe the frequency of the data: in a subsequent research step a multivariable statistical method, multi-correspondence analysis (MCA), was also undertaken; and finally,

(iii) Data visualization: Through GIS approaches, maps of the Alentejo area were compiled in order to explore the ways in which the data gathered in the survey were useful in the context of policy and decision making.

These three methodological steps listed above are further developed bellow followed by the results, discussion and conclusion sections.

\section{Data collection}

In order to implement a questionnaire survey in the Alentejo study area a set of eight municipalities were selected as representing the whole Alentejo region (for a more detailed explanation on the selection of case study areas please see Carvalho Ribeiro et al., 2013; Pinto Correia and Carvalho Ribeiro, 2012).

In the municipalities selected we surveyed the different social demands across the whole Alentejo region by means of questionnaire based interviews targeting at 200 landscape users in each user group. The sample was selected from each of 5 landscape user groups including: (i) inhabitants (local inhabitants and new comers - people that moved to the municipality), (ii) farmers, (iii) hunters, (iv) visitors (regular visitors and second house owners in the municipality), and tourists (tourists in general and eco-tourists-people 